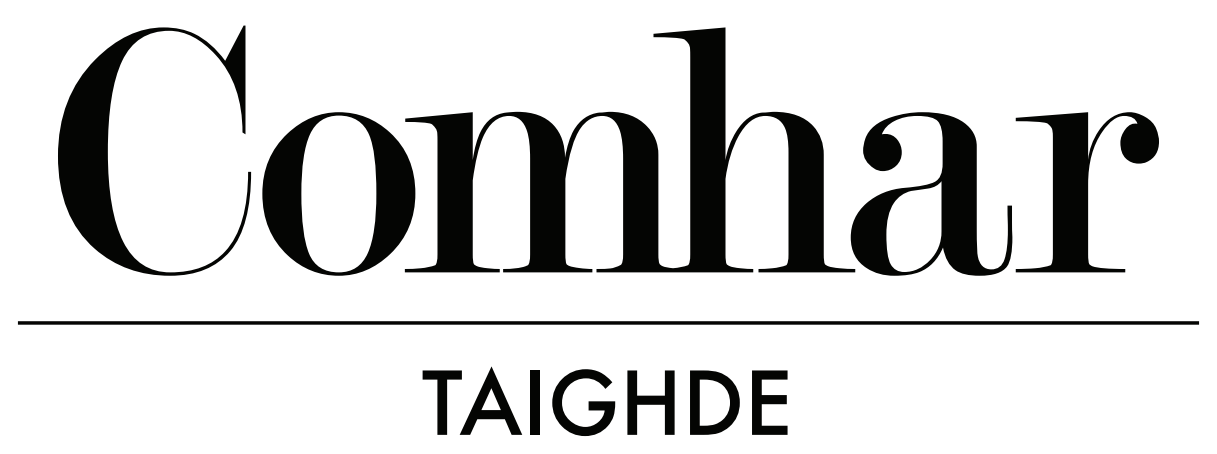

\title{
EAGRÁN 4
}

Samhain 2018

\section{Léirmheas}

Ag Siúl an Bhealaigh Mhóir: Aistí in ómós don Ollamh Nollaig Mac Congáil

Dáta foilsithe:

30 Samhain 2018

\section{Cóipcheart:}

(c) Charles Dillon, 2018

Seoladh gréasáin:

http://comhartaighde.com/eagrain/4/dillon/
Léirmheastóir:

Charles Dillon

\section{Comhfhreagras:}

c.dillon@ria.ie

Seoladh seasmhach (DOI):

https://doi.org/10.18669/ct.2018.06

Arna fhoilsiú ag COMHAR Teoranta le cabhair deontais i gcomhair tograí Gaeilge a d'íoc an tÚdarás um Ard-Oideachas trí Choláiste na hOllscoile, Corcaigh. Gabhann COMHAR buíochas le hAcadamh Ríoga na hÉireann as a dtacaíocht leis an bhfiontar seo.

\section{comhartaighde.ie}

ISSN: 2009-8626 


\title{
Ag Siúl an Bhealaigh Mhóir: Aistí in ómós don Ollamh Nollaig Mac Congáil
}

\author{
John Walsh agus Peadar Ó Muircheartaigh (eag.) \\ LeabhairCOMHAR (2016) | 480 Ich | ISBN: 978-0-9927313-8-0 | €20
}

Cnuasach aistí is ea é seo in ómós don Ollamh Nollaig Mac Congáil, fear a bhfuil clú ar fud shaol na Gaeilge air mar scoláire litríochta, mar thaighdeoir agus mar mhúinteoir teanga in Ollscoil na hÉireann, Gaillimh ón bhliain 1974 anall. Baineann ocht n-aiste dhéag an chnuasaigh le trí réimse léinn faoi leith atá mar mhacalla ar na spéiseanna taighde atá ag an té atá á cheiliúradh: Oidhreacht agus Litríocht Chúige Uladh; Irisí agus Nuachtáin na Gaeilge; Teangeolaíocht agus Canúineolaíocht na Gaeilge. Mar a thugtar le fios sa réamhrá, tá bealach fada taighde agus scoláireachta siúlta ag Nollaig Mac Congáil, agus is comhartha ómóis agus ceana é an fhéilscríbhinn seo a bheith i gcló mar chomóradh ar an tíolacadh atá fágtha aige agus an chomaoin faoina bhfuil lucht léinn na Gaeilge aige. Más fianaise ar bith uirthi sin méid, déanamh agus meáchan an leabhair stóinsithe seo, is mór an chomaoin í!

Is 1 an chéad rannóg, ina bhfuil ocht n-aiste, is toirtiúla de rannóga an leabhair. Baineann a mbunús sin le saothrú na litríochta in Ulaidh san fhichiú haois, agus ar ndóigh ba dheacair sin a dhéanamh sa leabhar seo gan muintir Mhic Grianna Rann na Feirste a chaibidil, go háirithe i bhfianaise ar chuir Mac Congáil féin i gcrích maidir le saothar ilchineálach an teaghlaigh sin a chur in eagar agus a iniúchadh le linn a ghairmréime. Tá aiste fhada bheathaisnéiseach ag Brian Ó Conchubhair a phléann le Seosamh Mac Grianna ina bhfuil insint ar an saol corrach a chaith an t-údar sin agus ar cén chaoi ar theip ar a shláinte. Tá léiriú maith san aiste ar an éagsúlacht sa taithí saoil a bhí ag Mac Grianna agus a leochailí a bhí an tallann scríbhneoireachta aige, agus ar na tubaistí a bhain dó idir bhás a mhic agus a mhná céile i 1959 . Aiste mhaith í a thugann cúlra sásta d'éinne a bheadh ag iarraidh tuiscint níos fearr a fháil ar an duine taobh thiar de na scríbhinní. Is é Lillis Ó Laoire a théann i mbun an chúraim Séamus Ó Grianna ('Máire') a chur faoi chaibidil, agus arís ní aiste den seandéanamh a chuireann sé ar fáil, ach díríonn ar ghné de chumadóireacht Mháire ar beag uile an trácht atá déanta uirthi - an t-amhrán 'Tráthnóna Beag Aréir' a chum sé. Tarraingíonn Ó Laoire ar an eolas fairsing atá aige ar thraidisiún amhránaíochta Dhún na nGall, idir Bhéarla agus Ghaeilge, le tuairimí meáite a chur ar fáil faoin tionchar a bhí ar Mháire a spreag é leis an amhrán a chumadh, agus luann 'The Heather Glen' go sonrach. Tá maoithneachas agus tocht an ghrá éagmaise le sonrú go fras i scéalta próis Mháire, agus léirítear anseo an bua a bhí aige an mothú sin a chur i bhfriotal idir cheolta agus scríofa. Dar liom gurb iad seo an dá aiste is fearr sa chéad chuid den leabhar, ach ní cáineadh ar bith é sin ar an cheathrar eile, óir ina measc sin tá cuntas an-luachmhar ag Philip O'Leary ar léiriú na staire i ndrámaí Shéamuis Uí Néill, agus cuntas spéisiúil ag Mícheál Mac Craith ar dhán Gaeilge atá ar leac chomórtha i séipéal i gColáiste na nGall sa Róimh ó 1626, scéal is féidir a chur leis na hailt iomadúla ina bhfuil insint tugtha ag Mac Craith dúinn faoi na Gaeil sa Róimh ón seachtú haois déag ar aghaidh. Féachann Nóilín Nic Bhloscaidh ar charachtar an chú sa bhéaloideas; tá cuntas spéisiúil ag Ríona Nic Congáil ar litríocht na n-óg i dTír Chonaill (1900-1930) agus cuireann 
Pádraig Ó Siadhail Earnán de Blaghd inár láthair trí fhéachaint ar a chuid dánta sin. Is spéisiúil go gcastar de Blaghd orainn chomh maith mar léirmheastóir in aiste Uí Chonchubhair agus lena chois sin mar Aire i rialtas an tSaorstáit a rinne iarracht fonn na stailce ocrais a bhaint de na cimí sa Droichead Nua i 1923. Bhí saol na Gaeilge beag, agus tá go fóill.

Ar ndóigh is mór a rinne Nollaig Mac Congáil le solas a chaitheamh ar an iriseoireacht Ghaeilge mar ghort uaibhreach taighde agus níl amhras ina fhéilscríbhinn ach go mbeadh fianaise ar an réimse sin, rud atá anseo go líonmhar. Arís tá aistí is fiúntaí ná a chéile sa rannóg, agus mar ancaire orthu tá cuntas den scoth ag Regina Uí Chollatáin ar na meáin Ghaeilge agus Éirí Amach 1916, agus an fhianaise atá iontu ar mheon na linne. Tá tábhacht nach beag ag baint le hanailís mar seo i gcomhthéacs an taighde nua go léir a spreag comóradh céad bliain an Éirí Amach. Nuair a mheabhraítear an nasc a mhaítear a bheith idir an Ghaeilge agus an pholaitíocht sa lá atá inniu ann, is cóir go mbeadh scéal na Gaeilge sa tréimhse chorraitheach sin á insint go tomhaiste mar atá anseo. Luaitear gur mar 'chogadh Bhaile Átha Cliath' a cuireadh síos in An Claidheamb Soluis ar an Éirí Amach agus rinneadh comparáid idir cogadh na cathrach sin agus an cogadh i bhFlóndras (322). Maidir le bás na gceannairí ina dhiaidh sin, rinneadh iad a chaí i gcomhthéacs a gcailliúna do ghluaiseacht na teanga seachas a n-éirim náisiúnaíoch ná mhíleata a bheith á móradh; toisc gur uirlis oifigiúil Chonradh na Gaeilge é An Claidheamb Soluis, míníonn Uí Chollatáin an dearcadh 'neamhpholaitiúil' mar chomhartha go rabhthas ag cloí le polasaí oifigiúil an Chonartha. Is deas an deis a bheith ag an léitheoir scéal agus traidisiún seo An Claidheamb Soluis a chur i gcomparáid le scéal na dtréimhseachán eile a bhain leis an Athbheochan, a bhuí le haistí ar 'irisí agus colúin réamh-Athbheochana' le Dorothy Ní Uigín agus ar 'Irisleabhar na Gaedhilge (1882-1909): Gníomh Dóchais na Teanga' le Liam Mac Peaircín. Tugann Ken Ó Donnchú léargas spéisiúil ar ailt Sheáin Uí Shúilleabháin (1903-1996) ar Scéala Éireann mar scáthán ar obair Choimisiún Béaloideasa Éireann. Is cuntas ríspéisiúil é ag Ó Donnchú ar an aighneas idir an dream ar chás leo béaloideas na hÉireann a bhailiú agus iad siúd ar mhó a n-aird ar obair na foilsitheoireachta. Ar ndóigh, de réir mar a chuaigh na blianta thart, bhí caomhnóirí an traidisiúin ag dul i ndísc, rud a d'fhág práinn le hobair an bhailithe. Pléann Ó Donnchú polaitíocht na saincheiste seo go spéisiúil. Meabhraíonn Dónall Ó Braonáin dúinn cén tábhacht a bhí le Scéala Éireann i dtaca le hábhair eile, sa mhéid gur ann a foilsíodh Cré na Cille i 1949 ina shraith nócha mír sular foilsíodh ina úrscéal clóite é. Mínítear an próiseas sin in aiste Uí Bhraonáin agus léirítear an ról a bhí ag ardán na n-irisí Scéala Éireann, Feasta agus Combar i gcur i láthair smaointeoireacht Uí Chadhain. Ar an iomlán, tá ábhar sa rannóg seo faoin iriseoireacht a sheasfadh mar fhoilseachán ann féin ar a oiread comhtháiteachta atá idir na haistí agus fiúntas an taighde atá le brath orthu, agus scéal tábhachtach idirghabháil na Gaeilge leis na meáin chlóite á insint go tomhaiste.

Sa tríu rannóg den leabhar, pléitear le cúrsaí teanga agus canúineolaíochta, agus más fíor gur teirce an líon scoláirí a shaothraíonn staidéar na teanga labhartha ná an líon a bhíonn gafa leis an litríocht scríofa, níl a shliocht sin ar chaighdeán na n-aistí atá anseo. Tá aiste bhreá ag Peadar Ó Muircheartaigh (comheagarthóir na féilscríbhinne) anseo a léiríonn leasú ceannródaíoch ar úsáid an Linguistic Atlas and Survey of Irish Dialects (LASID) agus éiríonn leis an chanúinmhéadracht a chur i bhfeidhm ar an fhianaise le léiriú a thabhairt dúinn ar dhifríochtaí agus ar chosúlachtaí idir canúintí éagsúla Gaeilge Uladh. Rinneadh léaráidí a ghiniúint a léiríonn go hanéifeachtach don tsúil cá bhfuil na cosúlachtaí agus na difríochtaí is suntasaí. Go deimhin is tógáil mhór í an aiste seo ar obair Mhic Congáil féin a rinne cur síos ar ghnéithe de chanúint Uladh in irisí léannta ar nós Éigse, Ériu agus Zeitschrift für Celtische Philologie. Is tráthúil anois a lua go bhfuil clár breá cuimsitheach de na saothair iomadúla ilchineálacha ag Mc Congáil san áireamh ag na heagarthóirí i dtosach an leabhair. Mar sin féin, dá gcuirfí na saothair sin in ord de réir réimsí, dar liom, seachas in ord dáta mar atá déanta, ba réidhe a thiocfadh léitheoir ar na sonraí atá uaidh faoi alt, agus fios aige cén réimse lena mbaineann sé, seachas cén dáta a foilsíodh é. Ina dhiaidh sin is uile, níl aon amhras ach gur údar mórshásaimh é a fheiceáil go bhfuil obair luachmhar cheannródaíoch fós ar siúl, a thógann ar an saothar a rinne Mac Congáil i réimse seo na teangeolaíochta. Tarraingíonn Caoimhín Mac Con Raoi ar LASID ar bhealach eile, 
ag leibhéal an fhocail, agus léiríonn dúinn cén leas a d'fhéadfadh an foclóirí a bhaint as an saothar sin, lena phlé ar théarmaíocht a bhaineann leis an bhó ar fud na gcanúintí. Ba mhaith a chuirfeadh an fhianaise atá ar fáil anois in Corpas Stairiuiil na Gaeilge 1600 1926 leis an staidéar seo (tháinig ann don leagan ar líne den Chorpas i mí Dheireadh Fómhair 2017, tar éis an leabhar seo bheith i gcló, ar an drochuair) óir d'fhéadfaí an fhianaise teangeolaíochta mar atá ar fáil in LASID a chur i gcomparáid lena bhféadfaí a bhleán d'fhianaise as corpas sin na litríochta. Féach, mar shampla, a leithéid seo thíos as an scéal rómánsaíochta Ceisneamb Inghine Guil (a foilsíodh i 1915) agus an toise breise a chuirfí le plé ar chiall agus ar chúlra na bhfocal loilioch agus gambnach ach an t-ábhar stairiúil liteartha a chur san áireamh: 'Níl ach anglais ag ár loilígheachaibh, agus iar ndísg ag ár ngabhnachaibh; agus nídh na lucha liatha léire luaithe ag lighe ár geneas mar iarradh bídh ó urthosach na h-oidhche go maidean.' Mar sin féin is ar theanga labhartha an fichiú haois agus ar fhianaise $L A S I D$ a bhí an t-údar ag díriú agus níl ann ach beadaíocht bheith ina dhiaidh seo air. Sa rannóg chéanna, cuireann John Walsh aiste eile leis na saothair iomadúla aige i réimse na sochtheangeolaíochta criticiúla, réimse léinn a bhfuil dealramh faoi ó thaobh na Gaeilge de le tamall de bhlianta anuas. San aiste seo scrúdaíonn sé próiseas an athraithe teanga agus dearcadh na muintire ina leith; sa chás seo is í Breac-Ghaeltacht na nDéise an fearann óna mbaintear fianaise. Is spéisiúil an ceantar é, ar ndóigh, le staidéar mar seo a thástáil óir is ann a bhí smaointeoireacht láidir faoin Ghaeilge agus faoin Athbheochan ar siúl i gcaitheamh fhichidí na haoise seo caite - agus tionchar dá réir, deir Walsh linn, ag Gaeilgeoirí an cheantair ar bheartais luatha an Rialtais i leith na Gaeltachta. Faigheann an t-údar a chuid fianaise ó fhoinsí éagsúla, agus ina measc siúd tá LASID (Wagner 1958-69), Sean-Chaint na nDéise (Sheehan 1944) agus na taifeadtaí fuaime a rinne Wilhelm Doegen sa cheantar an tráth céanna sin. Is spéisiúil fosta mar a tharraingíonn Walsh ar chín lae a bhí ag an bhailitheoir béaloidis Nioclás Breatnach, arbh as an cheantar chéanna é. In áit fianaise dá leithéid a obadh, toisc gur ó dhuine de bhunadh an cheantair a tháinig, agus é ag bailiú sonraí sa cheantar dílis céanna, is amhlaidh a dhíríonn Walsh ar a ról mar idirghabhálaí idir an pobal agus an tionscadal stáit
(Coimisiún Béaloideasa Éireann) a raibh sé d'aidhm aige oidhreacht bhéaloidis an phobail sin a chaomhnú. Mar sin tagann fianaise an Bhreatnaigh go cruinn le cuspóir na haiste an idé-eolaíocht a fhiosrú.

Cuireann an fhéilscríbhinn seo faoina coinne féin bheith ina comhartha ómóis don fhear léinn Nollaig Mac Congáil. Trí dhíriú ar thrí cinn de shainréimsí taighde atá in aice lena chroí ag Mac Congáil féin, agus trí mheitheal ildánach scríbhneoirí a mhealladh le bheith páirteach sa togra, d'éirigh go breá leis an chuspóir sin gan amhras. Ní áireofar cuid de na haistí anseo ar scoth an taighde a mhéadaíonn ár n-eolas ar shaíocht na Gaeilge, ach is dócha go bhfuil sinle tuiscint i gcomhthéacs féilscríbhinne nuair is tábhachtaí an t-ómós a léiriú trí bheith rannpháirteach sa mheitheal scríbhneoirí. Mar sin féin, don scoláire ar spéis leis na réimsí a chlúdaítear anseo, beidh neart lena spreagadh. Tá moladh mór tuillte ag na heagarthóirí as meitheal chomh mór sin a thabhairt le chéile, rud is teist ar dhea-chlú agus ar thíolacadh Nollaig Mhic Congáil do shaol an léinn.

Charles Dillon Acadamb Rioga na bÉireann

\section{SAOTHAIR A CEADAÍODH}

Triúr Comhalta de Chuallachta Cholm Cille. (1915). Gadaidhe Géar na Geamb-Oidhche. Baile Átha Cliath: Dollard/Gill. 